\title{
Effects of a protocol with manual therapy and postural techniques for non-specific low back pain
}

\author{
Daniele Alves da Silva', Maria Ester Ibiapina Mendes de Carvalho', Laiana Sepúlveda de Andrade Mesquita
}

\begin{abstract}
Background: The effects of postural reeducation on low back pain (LBP) are well documented in the literature, as well as studies using manual therapy (MT). However, no studies were found that investigate the use of a protocol using both MT and postural techniques. Objective: To verify the effects of a protocol that associates the MT and postural techniques in pain symptoms and functionality of subjects with chronic non-specific LBP. Methods: The participants of this study were 09 patients from the physiotherapy outpatient clinic of a public hospital. The evaluation of the subjects was carried out with the application of the Visual Analog Scale for Pain, Oswestry Disability Index (ODI) and Pressure Algometry. Patients were treated with a protocol composed of manipulative and postural techniques performed twice a week for five weeks. Two new evaluations were performed after the 5 th and 10 th sessions. For statistical analysis, the ANOVA test was used followed by the Tukey post-hoc test, considering $p<0.05$. Results: In all the evaluated variables it was observed a greater difference of the scores between the initial and the tenth evaluation. There was significant improvement in the pain ( $p=0.0167)$ and in the algometry of the piriformis and quadratus lumborum. There was no significant difference in disability $(p=0.0595)$. Conclusion: The protocol with MT and postural techniques promoted improvement of pain and increase of pressure sensitivity threshold in patients with chronic non-specific LBP.
\end{abstract}

KEYWORDS: Back Pain; Low Back Pain; Physiotherapy Techniques; Functionality; Spine.

\section{INTRODUCTION}

Low back pain (LBP) is a painful process in the lumbar region, considered chronic when it persists for 3 months or more, affecting most people at least once in life $\mathrm{e}^{(1)}$. In general, it is the pain syndrome that causes the most disability in relation to any other syndrome ${ }^{(2)}$, causing a considerable economic impact ${ }^{(3)}$. Among the risk factors are high age, low education, overweight or obesity, excessive physical effort, chronic diseases and anxiety ${ }^{(4)}$. However, most cases are classified as non-specific LBP, when it is not possible to identify an anatomopathological cause ${ }^{(5)}$. Since it is not possible to treat the cause directly, the treatment aims to reduce pain and its consequences. Thus, strategies are used such as educational activities focused on the patient, analgesic drugs and non-pharmacological therapies. In the list of non-pharmacological therapies are postural techniques and manipulations ${ }^{(6)}$.

The method of Global Postural Reeducation (GPR), developed by the French Philippe-Emmanuel Souchard is widely disseminated throughout the world. This method emphasizes the static function of the antigravitational muscles, taking into account their functional organization in two postural muscle chains: anterior and posterior ${ }^{(7)}$. The GPR postures seek to restore possible imbalances of forces between these two chains, associating tissue properties and muscle contraction, improving body symmetry, reducing functional disability and relieving pain ${ }^{(8,9)}$.

Manual Therapy (MT) is also widely used in the treatment of chronic LBP. The reduced mobility and biomechanical asymmetries present in $\mathrm{LBP}^{(10)}$ make manipulative techniques effective in the treatment of this painful syndrome in its several stages ${ }^{(11)}$. Both the effects of GPR and MT on LBP are documented in the literature ${ }^{(12,13)}$. However, no studies were found that investigate the use of a protocol that contemplates both MT and postural techniques. Thus, this research aimed to verify the effects of a protocol of MT and postural techniques on the pain and functionality of subjects with chronic non-specific LBP.

\section{METHODS}

This longitudinal study of quantitative approach was developed from August to November 2018. The research was approved by the Research Ethics Committee from the Universidade Estadual do Piauí, with number 2.609.765. The inclusion criteria was: patients of both genders; with age between 28 and 67 years; with persistent LBP for at least 
3 months, properly diagnosed and who did not have the following pathological conditions: nerve root compression, tumors, spinal surgery, vertebral fracture, severe scoliosis with respiratory problems, recent trauma, fibromyalgia, pregnancy, analgesic therapy of any nature, infectious diseases; and who agreed to participate spontaneously in the research by signing the Informed Consent Form according to the Resolution $\mathrm{n}$-466/2012. The following were excluded from the study: participants who had two consecutive absences during the treatment program, in addition to those who did not authorize or gave up their participation in the research. Eleven patients were evaluated, but 2 subjects could not continue the treatment for personal reasons and were disconnected from the research. Finally, the sample was composed of 09 patients of the physiotherapy clinic of a public hospital. After the signing of the informed consent form, the participants were submitted to a musculoskeletal evaluation in a reserved room of the outpatient clinic. To collect demographic data and follow the evolution of the patients, a datasheet was elaborated by the researchers. The pain symptomatology was first measured by the Visual Analogue Scale (VAS). This scale quantifies the intensity of pain through punctuated values, in which 0 (zero) indicates "no pain", and 10 (ten) points to "intense pain", thus being of clear understanding and easy application ${ }^{(14)}$. It was used the Oswestry Disability Index (ODI) to assess the patient's functionality. The questionnaire presents ten questions, with alternatives that score from 0 to 5 , related to activities of daily living (ADL). At the end of the application, the result is multiplied by two and the final score found and represented by percentage indicates the degree of incapacity of the subject ${ }^{(15)}$. Then it was used a digital algometer Wagner Instruments ${ }^{\circledR}$ (Wagner Instruments. Greenwich, CT, USA) with a capacity of ten kilograms-force (kgf) and compression deformation of $10 \mathrm{~cm}$, to evaluate the pain sensitivity threshold to palpation. After the patient's familiarization with the algometer, measurements were performed on the piriformis and the quadratus lumborum. For the evaluation of the piriformis, the patient was asked to position herself/himself in lateral decubitus (LD) and the area between the lateral of the sacrum and the greater trochanter was divided into three equivalent parts, the algometer being arranged between the 2nd and 3rd point, next to the greater trochanter. Still in LD, the instrument was positioned at the midpoint between the last rib and the iliac crest, to evaluate the quadratus lumborum ${ }^{(16)}$. The patient was asked to inform the researcher when the sensation of pressure became a painful sensation and then the value was recorded in the instrument. During the program, two new evaluations were performed in the same way as the initial evaluation, one after the 5 th session and the other just after the 10th. The program, prepared by the researchers, consisted of a total of ten sessions performed 2 times a week, each session consisting of 5 sessions of MT and 5 sessions of postural techniques performed alternately and starting with MT, according Table 3. The MT sessions had an average duration of 50 minutes. In the postural techniques, two postures were used per day, in which each one was maintained for the time that was possible within the limits of the patient, up to a maximum of 20 minutes. The number of repetitions of each manual technique varied during the session. In the first two sessions each technique was performed 5 times. In the third and fourth were performed 8 and in the fifth encounter 10 times. The application of the postures was divided in three moments, in which it was applied a different combination of postures in each one. In the first two sessions the postures used were "frog on the floor" and "frog in the air". In the third and fourth positions were "frog on the floor" and "sitting"; and in the fifth session the postures applied were "sitting" and "standing against the wall". All the techniques used in the protocol are described in Table 3. After data collection, the variables were processed in the BioEstat 5.0 program, and the mean and standard deviation were calculated. At first, it was checked whether there was normality of the variables using the Shapiro-Wilk test. As all variables followed normality, the ANOVA test was used, followed by the Tukey post-hoc test, considering $\mathrm{p}<0.05$.

\section{RESULTS}

Eleven patients were evaluated, but only 09, with an average age of 51.33 years, participated in this study. The characterization of the sample is described in Table 1. The complete evaluation was performed three times during the intervention program. Regarding pain assessed by VAS, there was a decrease in the score with a significant difference of the last (tenth) attendance in relation to the first one $(p=0.0167)$, as shown in figure 1 . Regarding the functionality evaluated by the ODI, it was observed that there was indeed an improvement in the score, but no significant difference $(p=0.0595)$, as shown in the Figure 2. Table 2 shows the data obtained with pressure algometry, in which it is possible to notice the increase in the pain sensitivity threshold, with a significant difference of the tenth attendance in relation to the initial evaluation. Analyzing the data from the three evaluations it was observed that a greater difference between the scores occurred between the second and third measurements, suggesting a minimum of 10 sessions to obtain a considerable clinical improvement.

Table 1: Characterization of the sample of patients with non-specific LBP from a public hospital in Teresina (PI), Brazil, 2018.

\begin{tabular}{cc}
\hline Variables & Mean/SD \\
\hline Age & $51.33 \pm 13.71$ \\
Weight $(\mathrm{kg})$ & $68.66 \pm 8.97$ \\
Height $(\mathrm{cm})$ & $158.00 \pm 5.17$ \\
BMI $\left(\mathrm{kg} / \mathrm{m}^{2}\right)$ & $27.53 \pm 3.53$ \\
\hline
\end{tabular}

Note: $\mathrm{Kg}$ - kilogram; $\mathrm{Cm}$ - centimeters; BMI - Body Mass Index; SD - Standard Deviation. 
Score

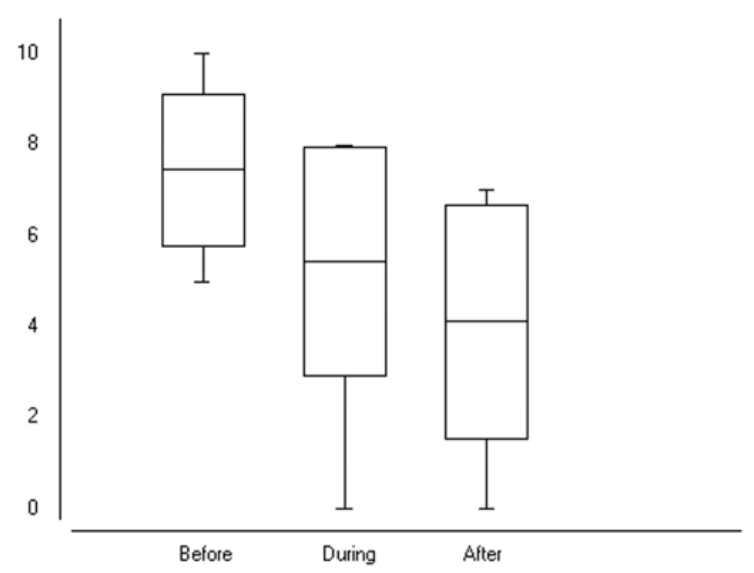

Note: Values represented by mean and standard deviation.

Figure 1: Pain assessment before, during and after the treatment program.

$\%$

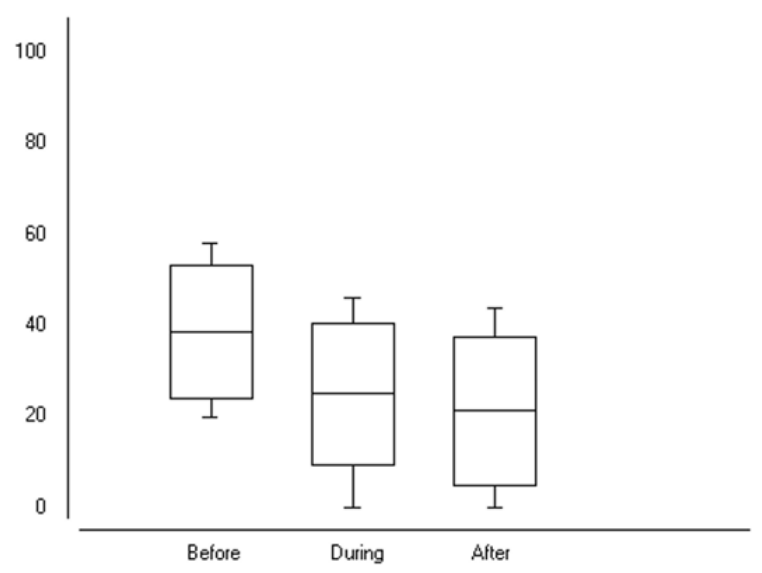

Note: Values represented by mean and standard deviation.

Figure 2: Functional disability assessment before, during and after the treatment program.

Table 2: Comparative data of Pressure Algometry before, during and after the treatment program.

\begin{tabular}{lcccc}
\hline & Assessment 1 & Assessment 2 & Assessment 3 & $P$ \\
\hline Piriformis R & $5.13 \pm 2.37$ & $8.58 \pm 3.97$ & $11.03 \pm 4.83^{*}$ & 0.0123 \\
Piriformis L & $4.81 \pm 1.78$ & $7.67 \pm 3.61$ & $10.97 \pm 3.99^{*}$ & 0.0025 \\
$\begin{array}{l}\text { Quadratus } \\
\text { Lumborum R }\end{array}$ & $4.91 \pm 2.06$ & $7.09 \pm 3.02$ & $9.39 \pm 3.99 *$ & 0.0195 \\
$\begin{array}{l}\text { Quadratus } \\
\text { Lumborum L }\end{array}$ & $4.51 \pm 2.29$ & $6.90 \pm 3.73$ & $9.54 \pm 4.03^{*}$ & 0.0172 \\
\hline
\end{tabular}

Note: R - Right; L - Left; * Significant difference in relation to the 1st evaluation by Tukey post-hoc after ANOVA.

\section{DISCUSSION}

Pain is defined as an unpleasant sensory experience, provoked by a nociceptive stimulus captured by free nerve endings distributed throughout the organism. The lumbar region has innumerable structures sensitive to pain, and because it is a highly requested segment of the daily living, the presence of a crisis leads to mobility restrictions with functional impairment for the subject ${ }^{(21)}$. MT has proved to be an important resource in pain modulation ${ }^{(10,11)}$, as well as in the functional restoration of structures affected by LBP. This is due to the fact that the manual techniques act directly or indirectly on the fascia, a connective tissue rich in collagen that exerts a direct participation in the transmission of forces ${ }^{(22)}$. The choice of performing the protocol starting with MT is justified in the inherent properties of the fascia and the effects of manual techniques on them. Among the principles applied to the fascia, it is highlighted the mechanotransduction, which corresponds to the process of conversion of a mechanical stimulus into a cellular biochemical response. This occurs because cells have their cytoskeleton anchored to the extracellular matrix by integrins. These proteins transmit the mechanical stress to the cellular membranes, and potentiate their protein synthesis ${ }^{(22-24)}$. The effects of mechanotransduction on fibroblasts are particularly important in view of the influence of collagen on tissue viscoelasticity. Langevin et al. ${ }^{(25)}$ found that the function of fascial slip is reduced in patients with LBP. Hypomobility due to pain promotes changes in connective tissue viscoelasticity and generates repercussions on the threshold of mechanoreceptor and free nerve endings, so that the use of manual techniques seeks, through mechanotransduction, to restore tissue elasticity and to relieve compression of the structures. The adoption of an antalgic posture after a crisis of LBP generates shortening that decomposes the balance of forces between the postural chains. GPR, through the stretching of the static muscles, seeks to reduce muscle tension, attenuating the overload in certain structures and restoring the range of physiological movement of the segment. Consequently there is reduction of discomfort and pain ${ }^{(11)}$. It is noted that, in a way, MT and postural techniques are complementary, and a program with both procedures is expected to have positive effects on pain, which was verified in this study when a significant improvement was observed both in the means evaluated with the VAS and in the pain sensitivity threshold to the pressure of the muscles tested. Soares et al. ${ }^{(26)}$, in a cross-sectional study on the relationship between disability, range of motion and pain, assessed patients with LBP and without LBP, noting that the pain level correlates directly with the degree of functional disability. This fact justifies the results found in this study with the ODI, in which, due to the improvement of pain, it was noticed an improvement in the means of the scores related to the functionality in the majority of the patients, although no significant difference was observed. This can be explained by 
Table 3. Protocol of the treatment of non-specific low back pain. Teresina (PI), Brazil, 2018.

\begin{tabular}{|c|c|}
\hline \multicolumn{2}{|r|}{ MANUAL THERAPY } \\
\hline Muscle / Segment / Technique & Description \\
\hline Diaphragm & $\begin{array}{l}\text { Unilateral Maneuver: Patient in Supine position (SP); the therapist with hands flat on the last ribs exerts } \\
\text { progressive pressure from the ribs to the belly button during expiration }{ }^{[17]} \text {. } \\
\text { Bilateral Maneuver: Patient in SP; the therapist exerts pressure with the thumbs along the lower edges of the } \\
\text { last ribs during expiration }{ }^{(17)} \text {. }\end{array}$ \\
\hline Psoas & $\begin{array}{l}\text { Pompage: Patient in SP; the therapist performs with one hand a deep massage on the Psoas and with the other } \\
\text { hand performs hip flexion at } 90^{\circ} \text { with adduction and compression }{ }^{(17)} \text {. }\end{array}$ \\
\hline Hamstrings & $\begin{array}{l}\text { Muscle-Energy: Patient in SP with lower limbs in hip flexion at } 90^{\circ} \text {; the therapist extends the patient's knee } \\
\text { until resistance is detected, requests and resists isometric contractions of knee flexion }{ }^{(17)} \text {. }\end{array}$ \\
\hline Lumbar Pompage & $\begin{array}{l}\text { Patient in prone position (PP); the therapist, with crossed forearms, place one hand at the level of the lower } \\
\text { thoracic and the other on the sacrum, and tighten up the lumbar pushing both hands in opposite directions }{ }^{(17)} \text {. }\end{array}$ \\
\hline Articulatory Technique & $\begin{array}{l}\text { Patient in PP with arms hanging; the therapist positions the pisiforms on the posterior thoracic joints and } \\
\text { during exhalation applies pressure towards the table with twisting of the wrists in opposite directions }{ }^{(17)} \text {. }\end{array}$ \\
\hline Piriformis & $\begin{array}{l}\text { Myofascial Release: With the patient in PP, the therapist locates the piriformis with an imaginary line between } \\
\text { the lateral of the sacrum and the major trochanter, makes contact with the elbow approximately } 3 \mathrm{~cm} \text { from the } \\
\text { sacrum and exerts a pressure in the anterior direction }{ }^{(18)} \text {. } \\
\text { Muscle-Energy: Patient in PP; the therapist bends the knee at } 90 \text { o and fixes the pelvis with one hand and with } \\
\text { the other performs internal rotation of the hip until resistance is detected, requests and resists isometric } \\
\text { contractions of the hip in external rotation }{ }^{(17)} \text {. }\end{array}$ \\
\hline Quadratus lumborum & $\begin{array}{l}\text { Patient in lateral decubitus of the opposite side to be treated; the therapist supports one forearm on the iliac, } \\
\text { the other on the ribs and hands together at the level of the lumbar spine, stretches the muscle by dropping the } \\
\text { weight of the body and abducting the arms keeping the hands together at all time }{ }^{(17)} \text {. }\end{array}$ \\
\hline \multicolumn{2}{|r|}{ POSTURAL TECHNIQUES } \\
\hline Technique & Description \\
\hline Frog on the floor & $\begin{array}{l}\text { Patient in SP; With the pelvis in retroversion the hips are flexed, abducted and externally rotated, in which the } \\
\text { soles of the feet must touch each other. Gradually, the lower limbs are extended as far as possible and within } \\
\text { the limits of the patient }{ }^{(17,19)} \text {. }\end{array}$ \\
\hline Frog in the air & $\begin{array}{l}\text { Patient in SP with the spine, lumbar and sacrum stabilized and the feet properly fitted in the belts of the GPR } \\
\text { stretcher. In the evolution of the posture the hips are gradually flexed until the maximum of } 90 \text {, the knees } \\
\text { extended and the ankles placed in dorsiflexion, without the pelvis losing the contact with the stretcher }{ }^{(17,19)} \text {. }\end{array}$ \\
\hline Sitting & $\begin{array}{l}\text { Patient sitting on ischial tuberosities, with legs flexed, hips in abduction and external rotation, and soles of } \\
\text { the feet in contact with each other. Gradually it is requested the extension and adduction of the legs with hip } \\
\text { flexion and ankle in dorsiflexion }{ }^{(17,20)} \text {. }\end{array}$ \\
\hline Standing against the wall & $\begin{array}{l}\text { Patient standing against the wall with retroverted pelvis, semi-flexed legs with hips in abduction and external } \\
\text { rotation and firm feet on the floor. The evolution of the posture happens with the gradual extension of the } \\
\text { legs }{ }^{(20)} \text {. }\end{array}$ \\
\hline
\end{tabular}

Note: Data Description: It describes in detail how to perform each technique of the MT and postural techniques used in this study for the treatment of chronic non-specific LBP.

the fact that disability was already moderate at the beginning of treatment. The limitations of this study are related to the sample size, which, because it was reduced, it was not possible to compare the results found with a control group.

\section{CONCLUSION}

According to the data obtained, it was observed that the proposed protocol of MT and postural techniques promoted significant improvement in pain and pressure sensitivity threshold in patients with chronic non-specific LBP. Although there was improvement, no significant difference was observed in relation to functional disability. However, further research is needed with a larger sample.

\section{AUTHORS' CONTRIBUTIONS}

DAS: study design, data collection and article writing; LSAM: study design, statistical analysis and data interpretation; MEIMC: study design and article review.

\section{CONFLICT OF INTERESTS}

The authors declare that there was no conflict of interests.

\section{REFERENCES}

1. Van Tulder M, Becker A, Bekkering T, Breen A, Del Real MT, Hutchinson $A$, et al. Chapter 3 European guidelines for the management of acute nonspecific LBP in primary care. Eur Spine J. 2006; 15(2): 169-91

2. Hoy D, March L, Brooks P, Blyth F, Woolf A Bain C, et al. The global burden of LBP: estimates from the Global Burden of Disease 2010 study. Ann Rheum Dis. 2014; 73: 968-74 
3. Filho NM, Silva GA. Invalidez por dor nas costas entre segurados da Previdência Social do Brasil. Rev Saúde Pública. 2011; 45(3): 494-502

4. Malta DC, Oliveira MM, Andrade SSCA, Caiaffa WT, Souza MFM, Berna, RTI. Fatores associados à dor crônica na coluna em adultos no Brasil. Rev Saude Publica. 2017; 51(Suppl 1)

5. Deyo RA, Weinstein JN. Low Back Pain.N Engl J Med. 2001; 344(5): 363-70

6. Maher C, Underwood M, Buchbinder R, Non-specific LBP. The Lancet. 2017; 389: 736-47

7. Ferreira GE, Barreto RGP, Robinson CC, Plentz, RDM; Silva, MF. Global Postural Reeducation for patients with musculoskeletal conditions: a systematic review of randomized controlled trials. Braz J Phys Ther. 2016; 20(3): 194-205

8. Bonetti F, Curti S, Mattioli S, Mugnai R, Vanti C, Violante FS, et al. Effectiveness of a 'Global Postural Reeducation' program for persistent LBP: a nonrandomized controlled Trial. BMC Musculoskeletal Disorders. 2010; 11: 285

9. Castagnoli C, Cecchi F, Canto AD, Paperini A, Boni R, Pasquini G, et al. Effects in Short and Long Term of Global Postural Reeducation (GPR) on Chronic LBP: A Controlled Study with One-Year Follow-Up. The Scientific World Journal. 2015

10. Briganó JU, Macedo CSG. Análise da mobilidade lombar e influência da terapia manual e cinesioterapia na lombalgia. Semina: Ciências Biológicas e da Saúde. 2005; 26(2): 75-82

11. Hidalgo B, Detrembleur C, Hall T, Mahaudens P, Nielens, H. The efficacy of MT and exercise for different stages of non-specific LBP: an update of systematic reviews. Journal of Manual and Manipulative Therapy. 2014; 22(2): 59-74

12. Lawand P, Júnior IL, Jones A, Sardim C, Ribeiro LH, Natour J. Effect of a muscle stretching program using the global postural reeducation method for patients with chronic LBP: A randomized controlled trial. Joint Bone Spine. 2015; 82(4): 272-77

13. Ulger O, Demirel A, Oz M, Tamer S. The effect of MT and exercise in patients with chronic LBP: Double blind randomized controlled trial. J Back Musculoskelet Rehabil. 2017; 30(6): 1303-09

14. Breivik H, Borchgrevink PC, Allen SN, Rosseland LA, Romundstad L, Hals EKB, et al. Assessment of pain. British Journal of Anaesthesia. 2008; 101(1): 17-24
15. Falavigna A, Teles AR, Braga GL, Barazzetti DO, Lazzaretti L, Tregnado AC. Instrumentos de avaliação clínica e funcional em cirurgia da coluna vertebral. Coluna/Columna. 2011; 10(1): 62-7

16. Imamura $M$, Alfieri FM, Filippo TRM, Battistella LR. Pressure pain thresholds in patients with chronic nonspecific LBP. Journal of Back and Musculoskeletal Rehabilitation. 2016, 29: 327-36

17. Almeida LC. Reeducação postural e sensoperceptiva: fundamentos teóricos e práticos. Rio de Janeiro: Medbook, 2006.

18. Ajimsha MS, Daniel B, Chithra S. Effectiveness of Myofascial release in the management of chronic LBP in nursing professionals. 2014; 18: 273-81.

19. Cunha ANV, Burke TN, França FJR, Marques AP. Effect of global posture reeducation and of static stretching on pain, range of motion, and quality of life in women with chronic neck pain: a randomized clinical trial. CLINICS. 2008, 63(6): 763-70

20. Silva EM, Andrade SC, Vilar MJ. Evaluation of the effects of global postural reeducation in patients with ankylosing spondylitis. Rheumatol Int. 2012; 32: 2155-2163.

21. Alleva J, Hudgins T, Belous J, Origrnes AK. Chronic LBP. Disease a Month. 2016

22. Schleip R, Findley T, Chaitow L, Huijing P. Fascia: the tensional network of the human body. Churchill Livingstone Elsevier, Edinburgh. 2012.

23. Chaitow L. Terapia manual para disfunção fascial. Artmed, Porto Alegre: 2017

24. Lima L, Jesus D, Lima A, Ermida V, Pacheco A, Pacheco I, et al. Mecanotransdução: Importância de Impor Stress na Reparação Tecidual, I Revista da Sociedade Portuguesa de Medicina Física e de Reabilitação. 2017; 29(1)

25. Langevin HM, Fox JR, Badger GJ, Greenan-Naumann AC, Bouffard NA, Konofagou EE, et al. Reduced thoracolumbar fascia shear strain in human chronic LBP. BMC Musculoskeletal Disorders. 2011; 12:203

26. Soares RS, Silva JAMG, Silva MGMG, Navega MT. Relação entre incapacidade funcional, amplitude de movimento e dor em indivíduos com e sem lombalgia. Ter Man. 2013; 11(51): 43-7 